
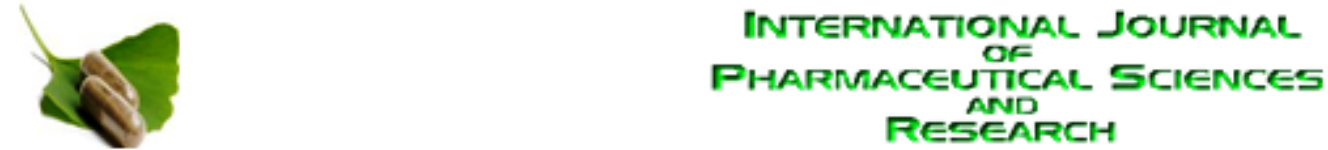

Received on 24 November, 2011; received in revised form 14 January, 2012; accepted 21 March, 2012

\title{
FORMULATION AND EVALUATION OF CONTROLLED POROSITY OSMOTIC TABLETS OF LORNOXICAM
}

\author{
A. Uma Maheswari*, K. Elango, Daisy Chellakumari, K. Saravanan and Anglina Jeniffer Samy
}

Department of Pharmaceutics, College of Pharmacy, Madras Medical College, Chennai-600003, Tamil Nadu, India

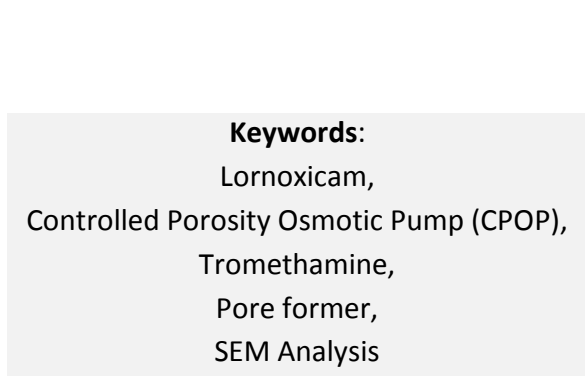

Correspondence to Author:

\section{A. Uma Maheswari}

Department of Pharmaceutics, College of Pharmacy, Madras Medical College,

Chennai-600003, Tamil Nadu, India

\section{ABSTRACT}

The aim of the present study is to formulate and evaluate controlled release formulation of lornoxicam based on osmotic technology. Lornoxicam, a potent non-steroidal anti-inflammatory drug (NSAID) with shorter half life, makes the development of sustained release (SR) dosage forms extremely advantageous. However, due to its weak acidic nature, its release from SR delivery system is limited to the lower GIT which consequently leads to a delayed onset of its analgesic action. Basic $\mathrm{pH}$ modifier tromethamine and wicking agent SLS were incorporated into the core tablet to create basic environmental $\mathrm{pH}$ inside the tablets, which provide complete drug release that starts in the stomach to rapidly alleviate the painful symptoms and continue in the intestine to maintain protracted analgesic effect. The effect of different formulation variables namely level of osmogen (mannitol) in the core tablet and level of pore former (sorbitol) in the coating membrane on in-vitro release was studied. Lornoxicam release from controlled porosity osmotic pump was directly proportional to the pore former (sorbitol) and level of osmogen (mannitol). Drug release from the developed formulations was independent of $\mathrm{pH}$ and agitational intensity and was dependent on osmotic pressure of the release media. Results of SEM studies showed the formation of pores in the membrane from where the drug release occurred. The optimized formulation was found to release the drug in zero order and found to be stable upon stability studies.
INTRODUCTION: Oral Controlled drug delivery is the one which delivers the drug at a predetermined rate, locally or systemically, for a specified period of time. Oral route has been the commonly adopted and most convenient route for the drug delivery. By considering the conventional dosage form of a drug and the drug profile data, such as dose, absorption rate constant, elimination rate constant, metabolic properties, drug properties and the quantity of drug needed, one can determine the desired release rate of the drug from controlled release dosage form. A variety of approaches and materials has been proposed, which could effectively be used in designing and construction of systems with potential to provide predictable, precise and reproducible pattern of controlled release or even site specific drug delivery ${ }^{1}$.

Osmotically controlled oral drug delivery system is the one which utilizes osmotic pressure for controlled delivery of active agent. Drug delivery from these systems, to a large extent, is independent of the physiological factors of the gastrointestinal tract. These systems can be utilized for systemic as well as targeted delivery of drugs. The release of drug from osmotic systems is governed by various formulation factors such as solubility and osmotic pressure of the core component, size of the delivery orifice, and nature of 
the rate-controlling membrane ${ }^{2}$. By optimizing formulation and processing factors, it is possible to develop osmotic systems to deliver drugs of diverse nature at a pre-programmed rate.

Lornoxicam is an extremely potent member of the oxicam group of NSAIDs that is widely used in management of pain associated with rheumatoid and osteoarthritis. It shows better GI tolerability compared to other NSAIDs which is extremely advantageous in terms of fewer side effects but due to its rapid elimination rate, repeated daily administration of lornoxicam is required to achieve long lasting and constant pain relief. Added to that, lornoxicam shows a distinct $\mathrm{pH}$-dependent solubility characterized by poor solubility in low $\mathrm{pH}$ conditions present in the stomach which consequently leads to delay in its analgesic effect ${ }^{3}$.

Thus, there is a strong clinical need and market potential for a dosage form that will deliver lornoxicam in a controlled manner to a patient needing this therapy, thereby resulting in a better patient compliance. The present study was aimed towards the development of controlled release formulations of lornoxicam based on osmotic technology. Different formulation variables were studied and optimized to achieve the desired release profile. The manufacturing procedure was standardized and the stability of the formulation was evaluated after 3 months of storage at accelerated stability conditions.

\section{MATERIALS AND METHODS:}

Chemicals: Lornoxicam was obtained as a gift sample from SKN Organics Private Limited, Pondicherry. Tromethamine and Sorbitol were purchased from S.D. Fine Chemicals, Mumbai. All other ingredients were obtained from ATOZ Pharmaceuticals, Chennai.

Compatibility Studies: Compatibility of Iornoxicam with different excipients was tested using FT-IR Spectrophotometer ${ }^{4}$.

Micromeritic Properties: The drug and blend of drug with excipients was evaluated for bulk density, tapped density, compressibility index, Hausner's ratio and angle of repose ${ }^{5}$.
Formulation of Lornoxicam Core Tablets: The core tablets of lornoxicam were prepared by wet granulation technique with varying ratios of the osmogen. Drug and all the ingredients except lubricants were weighed and passed through 20 mesh screen. To the resultant powder mixture, PVP dissolved in isopropyl alcohol was added to form a coherent mass. Then the coherent mass was passed through 16 mesh screen to form granules. The wet granules were dried at $50^{\circ} \mathrm{C}$ for 15 minutes. The dried granules were passed through 20 mesh screen to break the lumps and to get uniform size of granules. The lubricants were passed through 40 mesh screen and mixed with the dried granules.

The lubricated granules were compressed into tablets using $8.0 \mathrm{~mm}$ standard concave punches on a double rotary tablet machine. The composition of core tablets is listed in Table 1.

\section{TABLE 1: COMPOSITION OF CORE TABLET}

\begin{tabular}{ccccc}
\hline Ingredients & F01 & F02 & F03 & F04 \\
\hline Lornoxicam & 8 & 8 & 8 & 8 \\
Sodium Lauryl Sulphate & 12 & 12 & 12 & 12 \\
Tromethamine & 25 & 25 & 25 & 25 \\
Mannitol & 0 & 50 & 100 & 150 \\
Lactose & 187 & 137 & 87 & 37 \\
Povidone K30 & 12 & 12 & 12 & 12 \\
Magnesium Stearate & 2.5 & 2.5 & 2.5 & 2.5 \\
Talc & 2.5 & 2.5 & 2.5 & 2.5 \\
Aerosil & 1 & 1 & 1 & 1 \\
Isopropyl Alcohol & q.s & q.s & q.s & q.5 \\
\hline
\end{tabular}

Coating of Lornoxicam Osmotic Core Tablets: Three coating solutions of cellulose acetate in methanol and dichloromethane containing different levels of poreforming agent i.e., sorbitol $(0 \% \mathrm{w} / \mathrm{v}, 10 \% \mathrm{w} / \mathrm{v}$ and $20 \%$ $\mathrm{w} / \mathrm{v}$ ) were prepared for semi permeable membrane coating. PEG 400 acted as a hydrophilic plasticizer and was added to enhance the physical and mechanical property of cellulose acetate membrane.

The coating conditions were as follows: stainless steel pan, $200 \mathrm{~mm}$ diameter; rotation rate of the pan, 40 rpm; nozzle diameter of spray gun, $1 \mathrm{~mm}$; spray rate, 3 $\mathrm{ml} / \mathrm{min}$; drying temperature, $40^{\circ} \mathrm{C}$. After coating, the tablets were dried at $50^{\circ} \mathrm{C}$ to remove residual solvent. The coating compositions are listed in table 2 . 
TABLE 2: COMPOSITION OF COATING SOLUTION

\begin{tabular}{cccc}
\hline Ingredients & C1 & C2 & C3 \\
\hline Cellulose acetate & $60 \mathrm{~g}$ & $60 \mathrm{~g}$ & $60 \mathrm{~g}$ \\
Sorbitol & - & $6 \mathrm{~g}$ & $12 \mathrm{~g}$ \\
PEG 400 & $6 \mathrm{~g}$ & $6 \mathrm{~g}$ & $6 \mathrm{~g}$ \\
Water & $58 \mathrm{ml}$ & $58 \mathrm{ml}$ & $58 \mathrm{ml}$ \\
Dichloromethane & $870 \mathrm{ml}$ & $870 \mathrm{ml}$ & $870 \mathrm{ml}$ \\
Methanol & $580 \mathrm{ml}$ & $580 \mathrm{ml}$ & $580 \mathrm{ml}$ \\
\hline
\end{tabular}

Evaluation of Lornoxicam Osmotic Tablets: The osmotic tablets of lornoxicam were evaluated for uniformity of weight. Thickness and diameter were measured by vernier calipers. Hardness was determined by hardness tester and friability of osmotic tablets was determined by friabilator ${ }^{6}$.

Drug Content: Ten tablets were weighed and ground. The powder equivalent to $8 \mathrm{mg}$ of drug was taken, dissolved in methanol and phosphate buffer $\mathrm{pH} 6.8$ in the ratio of $1: 1$ and suitably diluted. The absorbance of the resulting solution was measured at $376 \mathrm{~nm}$ and the amount of lornoxicam was calculated ${ }^{7}$.

Drug Content Uniformity: Ten tablets were randomly selected and tested for their drug content. Each tablet was powdered, $50 \mathrm{ml}$ of methanol was added, shaken for 30 minutes and $6.8 \mathrm{pH}$ phosphate buffer was added to produce $100 \mathrm{ml}$. It was then centrifuged. $10 \mathrm{ml}$ of the supernatant liquid was taken and diluted to $100 \mathrm{ml}$ with $6.8 \mathrm{pH}$ phosphate buffer. The absorbance of resulting solution was measured at the maximum at about $376 \mathrm{~nm}$ and the content of lornoxicam was calculated and compared with the label claim ${ }^{8}$.

In-vitro release study of the Tablets: Two stepdissolution conditions were carried out in a USP Type II (paddle) dissolution apparatus to simulate the physiological conditions of GIT: 2 hours in $900 \mathrm{ml}$ of simulated gastric fluid (SGF, pH 1.2) and remaining 22 hours in $900 \mathrm{ml}$ of simulated intestinal fluid (SIF, pH 6.8). The stirring rate was $100 \mathrm{rpm}$ and the temperature was maintained at $37 \pm 0.5^{\circ} \mathrm{C}$. Aliquots of dissolution medium were withdrawn at predetermined time intervals and the same volume of medium was replenished to maintain the consistent volume ${ }^{9}$.

Effect of change in agitation speed on Drug Release: In order to study the effect of agitational intensity on the optimized formulation, release study was also performed in dissolution apparatus at various rotational speeds of 50, 100 and $150 \mathrm{rpm}$ using two step-dissolution conditions ( 2 hours in $900 \mathrm{ml}$ of SGF $\mathrm{pH} 1.2$, and remaining 22 hours in $900 \mathrm{ml}$ of SIF pH 6.8) in a USP Typell dissolution apparatus. The temperature was maintained at $37 \pm 0.5^{\circ} \mathrm{C}$. The release was studied at predetermined time intervals ${ }^{10}$.

Effect of pH on Drug Release: In order to study the effect of $\mathrm{pH}$ of release medium in the drug release of optimized formulation, the in vitro release studies can be carried out in buffers of different $\mathrm{pH}$, like $\mathrm{pH} 1.2$ buffer, $\mathrm{pH} 4.5$ acetate buffer, and $\mathrm{pH} 6.8$ phosphate buffer in USP type II dissolution apparatus. The temperature was maintained at $37 \pm 0.5^{\circ} \mathrm{C}$. The release was studied at predetermined time intervals ${ }^{11}$.

Effect of Osmotic Pressure: To confirm the major mechanism of drug release, release study of the optimized formulation was conducted in release media of different osmotic pressure. To increase the osmotic pressure of the release media (pre-equilibrated to $37^{\circ} \mathrm{C}$ $\pm 1^{\circ} \mathrm{C}$ ); mannitol (Osmotically effective solute) was added to produce $1.5 \mathrm{~atm}, 3 \mathrm{~atm}$ and $4.5 \mathrm{~atm}$ respectively. The release was studied at pre determined time intervals ${ }^{12}$.

\section{Membrane Morphology of Porous Osmotic Tablet:}

Scanning Electron Microscopy: Coating membranes of formulation obtained before and after complete dissolution of core contents were examined for their porous morphology by scanning electron microscope. Membranes were dried at $45^{\circ} \mathrm{C}$ for 12 hours and stored between sheets of wax paper in a dessicator until examination. The membrane was coated under an argon atmosphere with gold-palladium, and observed with a scanning electron microscope ${ }^{12}$.

Release Kinetics of the Optimized Formulation: The in-vitro release data of the optimized batch was fitted to various kinetic models (Zero-order, First-order, Higuchi, Hixson - Crowell and Korsmeyer-Peppas models). The best fit was found out to describe the kinetics of drug release ${ }^{12,13}$.

Stability Studies: The optimized batch was subjected to the stability study at accelerated condition of $40^{\circ} \mathrm{C} /$ $75 \% \mathrm{RH}$ for a period of 3 months. Optimized formulation was packed in blister and stored in stability chambers maintained at $40^{\circ} \mathrm{C}$ and $75 \% \mathrm{RH}$ for 
three months. After every month tablet samples were analyzed for physical appearance, drug content and invitro release ${ }^{14}$.

\section{RESULTS AND DISCUSSION:}

Compatibility study: From the FT-IR study the drug was found to be compatible with all the excipients.
Micromeritic Properties: The lornoxicam powder blends were free flowing as indicated by the values of bulk density $(0.479$ to $0.510 \mathrm{gm} / \mathrm{ml})$, tapped density ( 0.534 to $0.585 \mathrm{gm} / \mathrm{ml}$ ), compressibility index (10.29 to $12.82 \%)$ and Hausner ratio (1.11to 1.14). Angle of repose ranged from 17.28 to 19.44 . The values are given in table 3.

TABLE 3: MICROMERITIC PROPERTIES OF DRUG AND POWDER BLEND

\begin{tabular}{cccccc}
\hline Drug and Formulation Blends & Bulk Density* $(\mathrm{g} / \mathbf{m l})$ & Tapped Density* $(\mathrm{g} / \mathrm{ml})$ & Compressibility Index* $(\%)$ & Hausner's Ratio & Angle of Repose \\
\hline Drug & $0.711 \pm 0.002$ & $1.103 \pm 0.002$ & $35.53 \pm 0.16$ & $1.55 \pm 0.06$ \\
F01 & $0.510 \pm 0.004$ & $0.585 \pm 0.007$ & $12.82 \pm 0.21$ & $1.14 \pm 0.03$ \\
F02 & $0.489 \pm 0.002$ & $0.560 \pm 0.002$ & $12.67 \pm 0.24$ & $19.44 \pm 0.16$ \\
F03 & $0.479 \pm 0.003$ & $0.534 \pm 0.006$ & $10.29 \pm 0.28$ & $17.28 \pm 0.64$ \\
F04 & $0.489 \pm 0.005$ & $0.560 \pm 0.008$ & $12.67 \pm 0.34$ & $1.11 \pm 0.05$ & $1.14 \pm 0.09$ \\
\hline
\end{tabular}

* Mean of 3 readings

Physical Evaluation and Drug Content: The lornoxicam osmotic tablets were uniform in weight $(0.275$ to $0.278 \mathrm{~g}$ ) and the thickness ( 3.54 to $3.58 \mathrm{~mm}$ ) and diameter $(8.912$ to $8.966 \mathrm{~mm})$ of the tablets were uniform. The hardness of coated tablets was found to be between 5.2 and $5.8 \mathrm{~kg} / \mathrm{cm}^{2}$, while the friability of

TABLE 4: PHYSICAL EVALUATION AND DRUG CONTENT

\begin{tabular}{|c|c|c|c|c|c|c|}
\hline Formulation & $\begin{array}{c}\text { Uniformity of } \\
\text { weight }^{\#} \text { (g) }\end{array}$ & $\begin{array}{l}\text { Diameter* } \\
(\mathrm{mm})\end{array}$ & $\begin{array}{c}\text { Thickness* } \\
\text { (mm) }\end{array}$ & $\begin{array}{c}\text { Hardness* } \\
\left(\mathrm{kg} / \mathrm{cm}^{2}\right)\end{array}$ & Friability (\%) & $\begin{array}{c}\text { Drug content } \\
(\% w / w)\end{array}$ \\
\hline F01C1 & $0.278 \pm 0.003$ & $8.966 \pm 0.021$ & $3.542 \pm 0.015$ & $5.7 \pm 0.273$ & $0.10 \pm 0.023$ & $100.8 \pm 1.403$ \\
\hline F01C2 & $0.277 \pm 0.004$ & $8.952 \pm 0.031$ & $3.538 \pm 0.029$ & $5.7 \pm 0.447$ & $0.16 \pm 0.021$ & $95.61 \pm 0.894$ \\
\hline F01C3 & $0.277 \pm 0.002$ & $8.956 \pm 0.021$ & $3.568 \pm 0.019$ & $5.6 \pm 0.418$ & $0.15 \pm 0.019$ & $95.61 \pm 0.894$ \\
\hline F02C1 & $0.278 \pm 0.003$ & $8.946 \pm 0.048$ & $3.560 \pm 0.025$ & $5.7 \pm 0.273$ & $0.15 \pm 0.022$ & $100.91 \pm 0.95$ \\
\hline $\mathrm{F} 02 \mathrm{C} 2$ & $0.277 \pm 0.002$ & $8.912 \pm 0.042$ & $3.546 \pm 0.017$ & $5.5 \pm 0.353$ & $0.14 \pm 0.026$ & $99.08 \pm 1.110$ \\
\hline F02C3 & $0.277 \pm 0.003$ & $8.950 \pm 0.010$ & $3.574 \pm 0.009$ & $5.6 \pm 0.418$ & $0.13 \pm 0.021$ & $97.29 \pm 0.998$ \\
\hline F03C1 & $0.277 \pm 0.002$ & $8.954 \pm 0.023$ & $3.542 \pm 0.035$ & $5.5 \pm 0.353$ & $0.12 \pm 0,028$ & $95.26 \pm 0.987$ \\
\hline F03C2 & $0.277 \pm 0.002$ & $8.952 \pm 0.032$ & $3.580 \pm 0.016$ & $5.2 \pm 0.570$ & $0.22 \pm 0.024$ & $99.46 \pm 1.098$ \\
\hline F03C3 & $0.276 \pm 0.002$ & $8.960 \pm 0.010$ & $3.568 \pm 0.013$ & $5.9 \pm 0.273$ & $0.18 \pm 0.021$ & $97.15 \pm 1.143$ \\
\hline F04C1 & $0.275 \pm 0.002$ & $8.934 \pm 0.040$ & $3.566 \pm 0.005$ & $5.3 \pm 0.447$ & $0.62 \pm 0.022$ & $95.98 \pm 0.987$ \\
\hline $\mathrm{F} 04 \mathrm{C} 2$ & $0.276 \pm 0.001$ & $8.966 \pm 0.015$ & $3.570 \pm 0.033$ & $5.8 \pm 0.570$ & $0.71 \pm 0.027$ & $98.33 \pm 1.056$ \\
\hline F04C3 & $0.277 \pm 0.002$ & $8.960 \pm 0.007$ & $3.566 \pm 0.005$ & $5.5 \pm 0.500$ & $0.70 \pm 0.023$ & $99.05 \pm 1.123$ \\
\hline
\end{tabular}

* Mean of 5 readings. \# Mean of 20 readings

osmotic tablets ranged between $0.10 \%$ and $0.71 \%$. The tablets have enough hardness to withstand stress during transport and handling. The drug content in various formulations varied between $95.61 \%$ and 100.91\% w/w (Table 4).

Uniformity of Drug content: All the formulations exhibited uniformity of drug content ${ }^{8}$.

In-vitro release study of the Tablets: All the formulations were subjected to in vitro release study. The formulation F04C2 containing $60 \%$ of mannitol in core tablet and $10 \%$ of sorbitol in coating membrane has controlled release of drug for 24 hours (Figure 1).

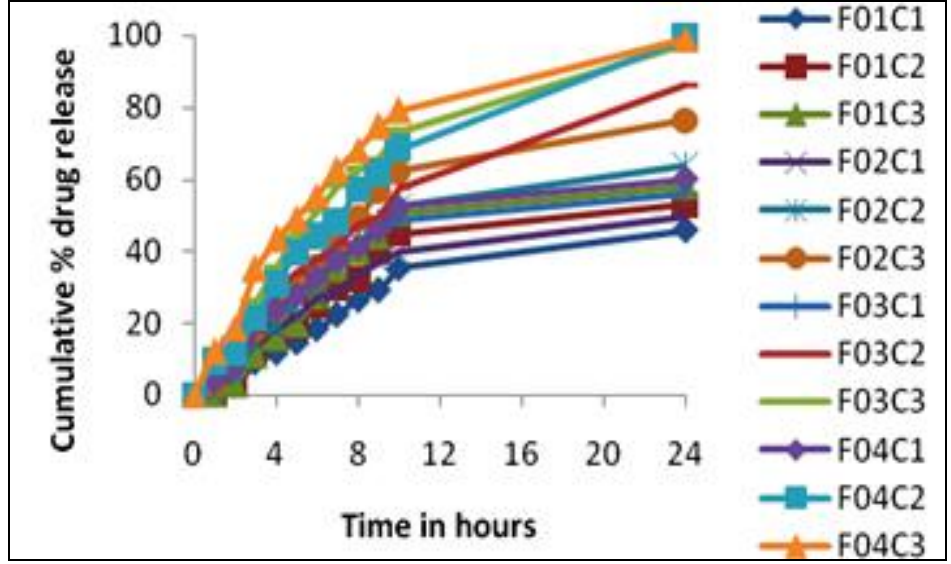

FIGURE 1: RELEASE STUDY OF VARIOUS FORMULATIONS 
Effect of Osmogen Concentration on Drug Release: The effect of osmogen concentration on drug release is shown in the figure 2 .

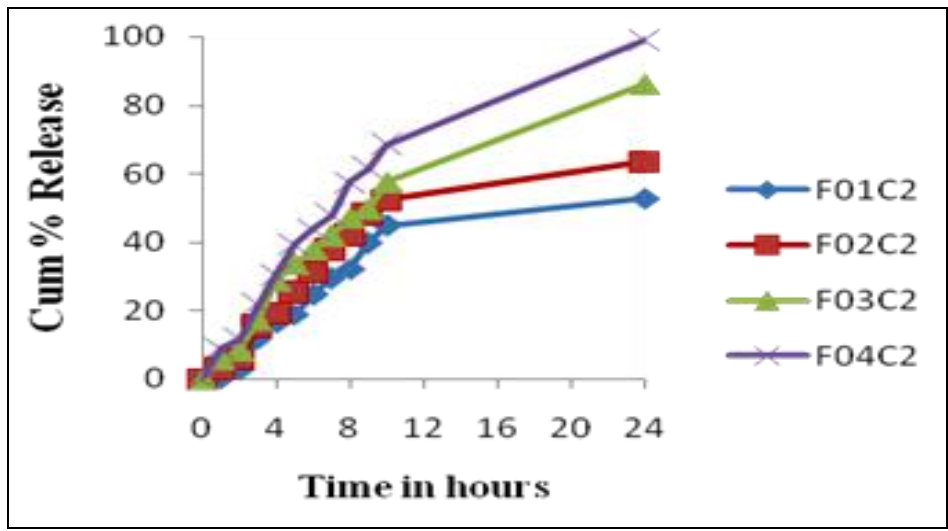

FIGURE 2: EFFECT OF OSMOGEN CONCENTRATION ON DRUG RELEASE

Increase in concentration of mannitol increases the drug release. Higher the amount of osmogen, greater is the driving force to release the drug. This is because increase in osmogen concentration increases the osmotic pressure inside the tablet and thus the drug release is increased (Figure 2).

Effect of concentration of pore forming agents on drug release: The effect of concentration of pore forming agents on drug release is shown in figure 3. Three different coatings $\mathrm{C} 1, \mathrm{C} 2, \mathrm{C} 3$ contain $0 \%, 10 \%$, and $20 \%$ of sorbitol as pore forming agent were selected.

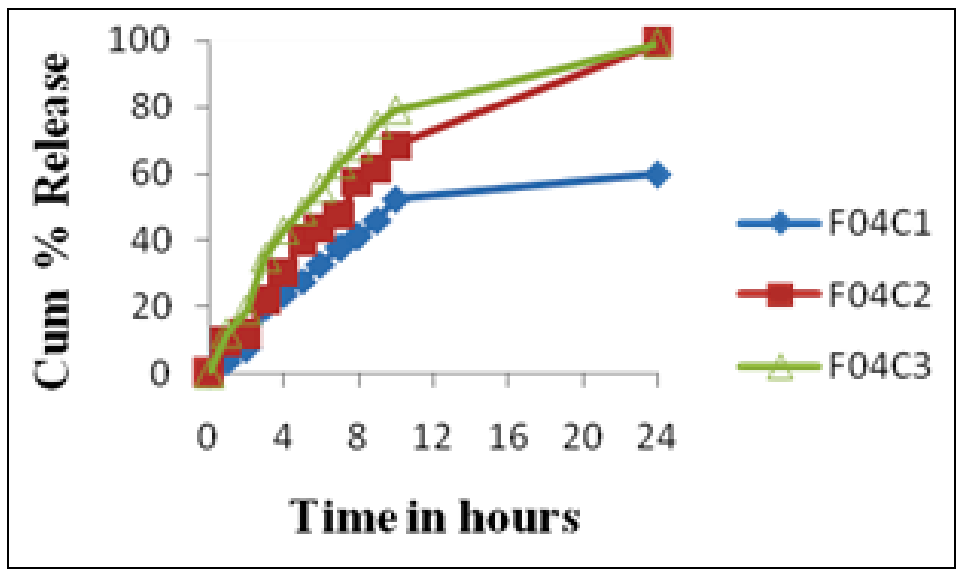

FIGURE 3: EFFECT OF CONCENTRATION OF PORE FORMING AGENTS ON DRUG RELEASE

Increase in the level of pore former increases the membrane porosity due to more number of pores formed in the membrane, resulting in faster drug release (Figure 3).
Effect of Agitation Speed on the Drug Release: The effect of agitation speed on drug release is shown in figure 4.

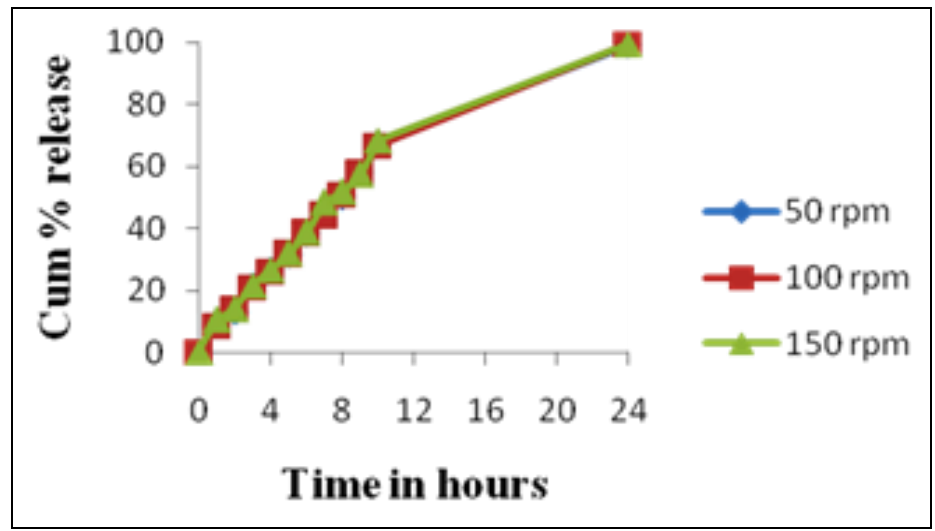

FIGURE 4: EFFECT OF SPEED OF ROTATION ON DRUG RELEASE

The speed of rotation doesn't have much effect on drug release. Therefore the motility of gastrointestinal tract might scarcely affect the drug release. (Figure 4)

Effect of pH on Drug Release: The effect of pH on drug release is shown in figure 5 .

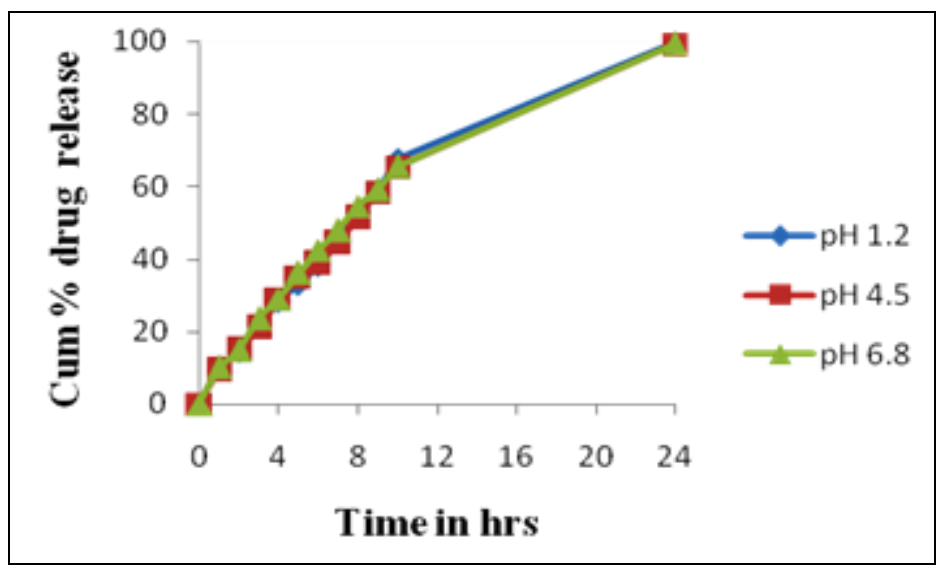

FIGURE 5: EFFECT OF pH ON DRUG RELEASE

The results shows that the $\mathrm{pH}$ of release medium does not have significant effect on drug release. Thus the fluid in different parts of gastrointestinal tract will scarcely affect the drug release (Figure 5).

Effect of Osmotic Pressure on Drug Release: The effect of change in osmotic pressure on drug release is shown in figure 6 . 


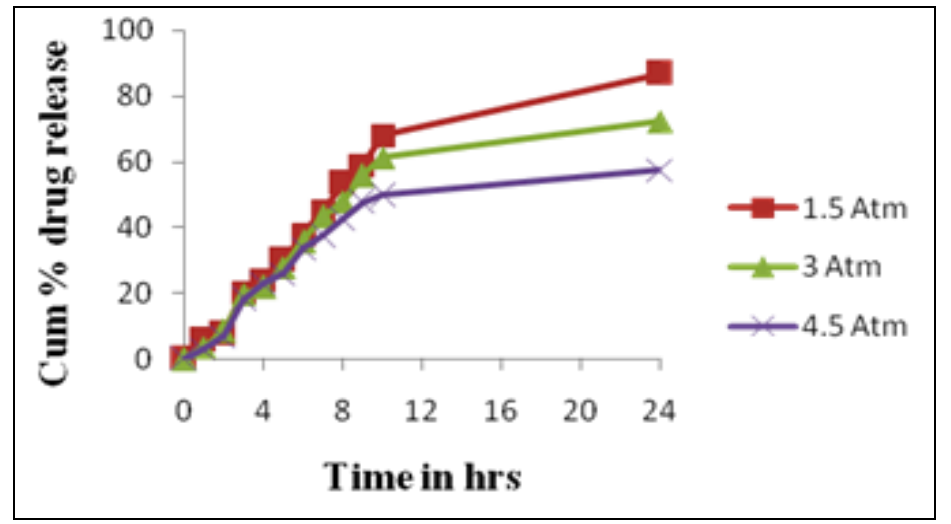

FIGURE 6: EFFECT OF OSMOTIC PRESSURE ON DRUG RELEASE

It is evident that the drug release from the formulation decreased as the osmotic pressure of the medium increased. This confirms that the mechanism of drug release is by osmotic pressure.

\section{Membrane morphology of Porous Osmotic Tablets:} Membranes obtained before dissolution clearly showed non porous region (Figure 7a, 8a). After 24 hours of dissolution the membrane showed pores formed owing to the dissoution of sorbitol from the membrane, (Figure $\mathbf{7 b}, \mathbf{8 b}$ ). The formulation with $\mathrm{C2}$ coating containing $10 \%$ sorbitol produced less pores (Figure 7b) compared to formulation C3 coating containing $20 \%$ sorbitol (Figure 8 b).

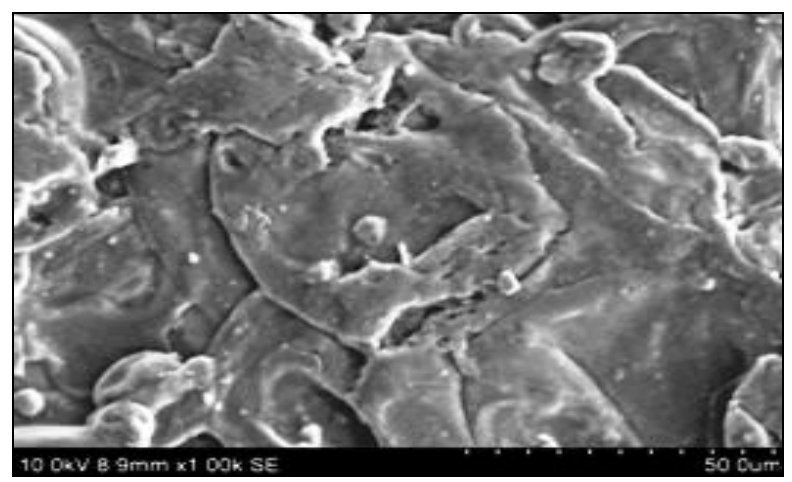

a) BEFORE DISSOLUTION

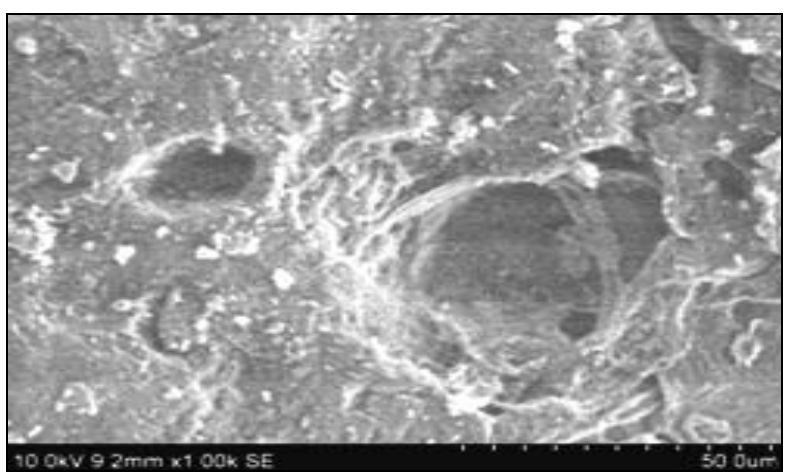

b) AFTER DISSOLUTION

FIGURE 7: MEMBRANE MORPHOLOGY OF FORMULATION F04C2 BY SCANNING ELECTRON MICROSCOPY

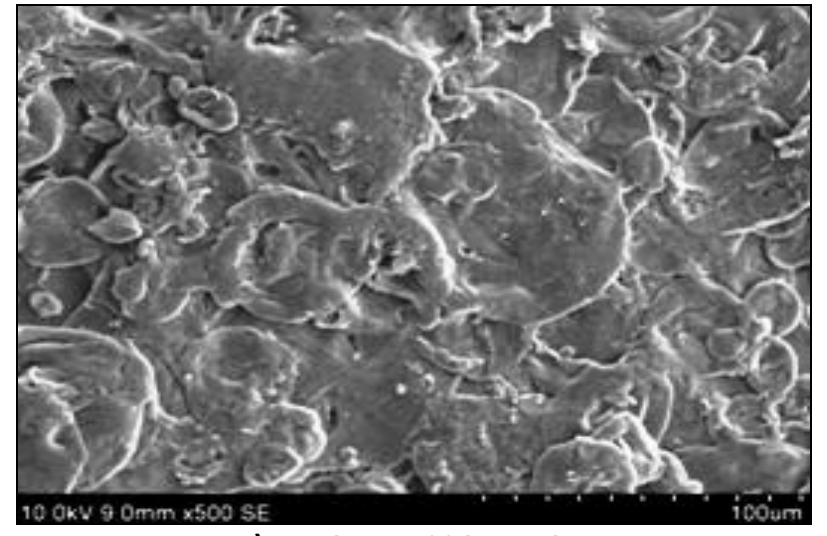

a) BEFORE DISSOLUTION

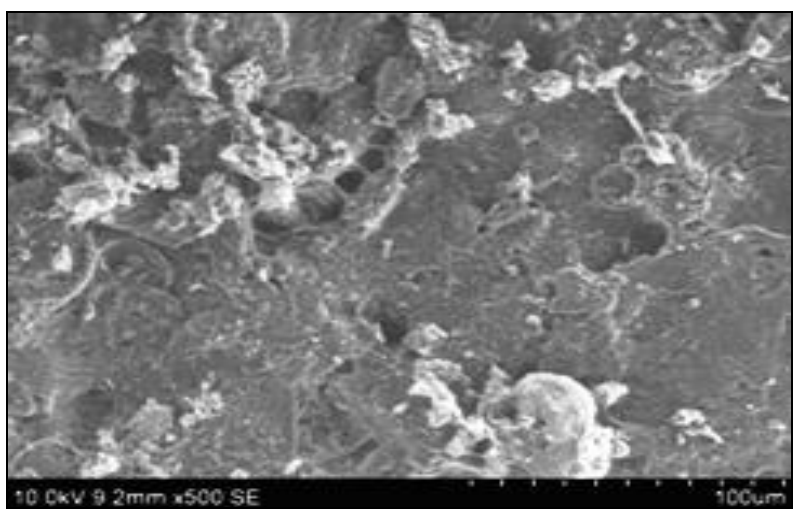

b) AFTER DISSOLUTION

FIGURE 8: MEMBRANE MORPHOLOGY OF FORMULATION F04C3 BY SCANNING ELECTRON MICROSCOPY

Release Kinetics of the Optimized Formulation: The $\mathrm{R}^{2}$ values for various release models are 0.9443 for zero order, 0.8639 for first order, 0.9714 for Higuchi, 0.8126 for Korsemeyer Peppas and 0.9815 for Hixson Crowell kinetics. The drug release follows zero order kinetics and the mechanism followed is Hixson Crowell (Figure 9 and 10).

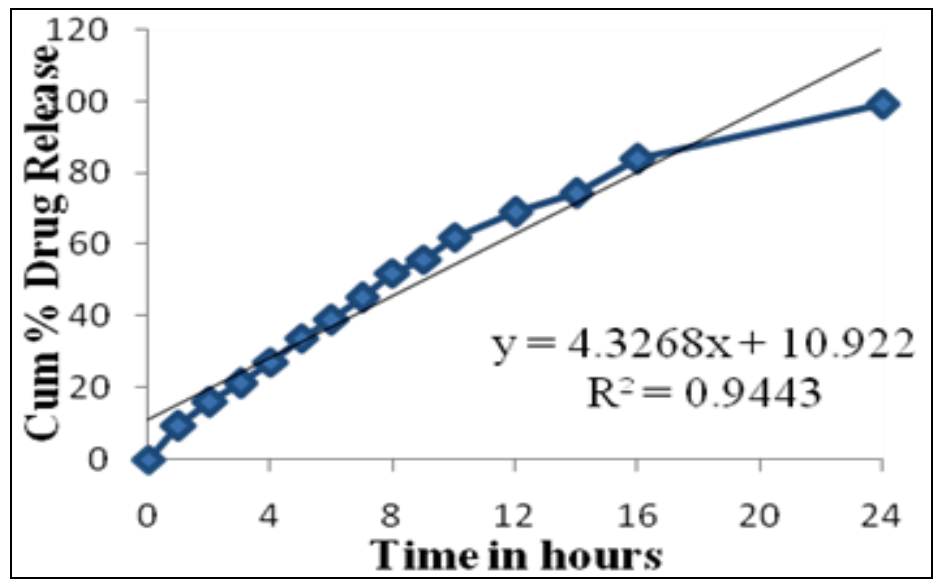

FIGURE 9: A PLOT OF ZERO ORDER KINETICS 


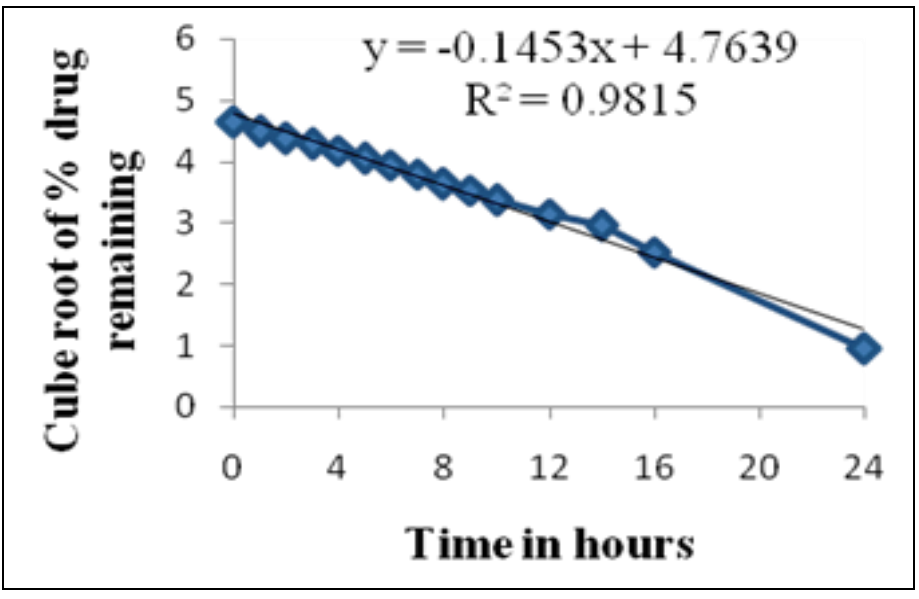

FIGURE 10: PLOT OF HIXSON-CROWELL KINETICS

Stability Studies: The osmotic tablets (F04C2) were stored at $40^{\circ} \mathrm{C} / 75 \% \mathrm{RH}$ for 3 months, there was no change either in physical appearance or in drug content. The dissolution study was conducted in the simulated physiological environment of stomach $(\mathrm{pH}$ 1.2), and intestine ( $\mathrm{pH} 6.8)$, not much difference was observed in the cumulative percentage release of lornoxicam from F04C2. Hence the formulation was found to be stable.

CONCLUSION: Lornoxicam controlled porosity osmotic tablet was developed. Of the several formulations investigated, the formulation (F04C2) containing mannitol $60 \%$ in the core tablet and $10 \%$ of sorbitol in the semipermeable membrane as pore former has come out successfully to comply with the requirements for controlled release formulations. The osmotic pressure exerted by the osmogen in the core tablet and the amount of pore former in the semipermeable membrane controlled the drug release.

ACKNOWLEDGEMENT: The authors are thankful to ATOZ Pharmaceuticals, Chennai, for providing facilities to carry out the Research work.

\section{REFERENCES:}

1. Vyas SP, Roop K Khar: Controlled Drug Delivery - Concepts and Advances. Delhi: Vallabh Prakashan, First edition 2002.

2. Tanmoy Ghosh, Amitava Ghosh: Drug delivery through osmotic systems-an overview. Journal of Applied Pharmaceutical Science 2011; 1: 38-49.

3. Yassin El-Said Hamza, and Mona Hassan Aburahma: Design and in vitro evaluation of novel sustained-release matrix tablets for lornoxicam based on the combination of hydrophilic matrix formers and basic $\mathrm{pH}-$ modifiers. Pharmaceutical Development and Technology 2010; 15: 139-153.

4. A Choudhury, S Das, S Bahadur, S Saha, A Roy: Formulation and evaluation of omeprazole tablets for duodenal ulcer. Indian Journal of Pharmaceutical Sciences 2010; 72: 491-494.

5. Dinanath Gaikwad, Jadhav RT, Amol Limkar, Sangeeta, Kisan Bobe, Manoj Patil, Trushali Khade, Bhaskar Gavitre, Vivek Kulkarni, Uday Gaikwad: Formulation and Evaluation of Sustained Release Tablet of Aceclofenac by Film Coating. International Journal of Research in Pharmaceutical and Biomedical Sciences Jan - Mar 2011; 2: 310-318.

6. SH Lakade, Bhalekar MR: Formulation and Evaluation of Sustained Release Matrix Tablets of Anti-Anginal drug, Influence of combination of hydrophobic and hydrophilic matix former. Research J. Pharm. and Tech. Jan - Mar 2008; 1: 410-413.

7. Hariprasanna R. C, Qamar Jamal Ahmad, Upendra kulkarni. Design and Evaluation Twice Daily Lornoxicam Bi-Layer Matrix Tablets by Using Hydrophilic polymer Sodium Alginate. Asian Journal of Biochemical and Pharmaceutical Research 2011; 1:2231-2560.

8. Indian Pharmacopoeia. Vol. II, Ghaziabad: Indian Pharmacopoeia Publication, 1996.

9. Mohd Azharuddin, Krishnananda Kamath, T. Panneerselvam, Subash S. Pillai, A.R.Shabaraya: Formulation and evaluation of controlled release matrix tablets of antihypertensive drug using natural and synthetic hydrophilic polymers. Research in Biotechnology 2011; 2: 26-32.

10. Shivanand Pandey, Paridhi Shukla: Formulation and Evaluation of Osmotic Pump Delivery of Oxybutynin. International Journal of PharmTech Research. Oct - Dec 2009; 1: 1638-1643.

11. Hussan Raza, Sancheti Vikram N, Kumaravelrajan R: Formulation and Optimization of Aceclofenac Monolithic Osmotic Pump. International Journal of Pharmaceutical Sciences Review and Research. 2011 Jan Feb; 6: 42-47.

12. Sudeesh Edavalath, Shivanand K, Kalyani Prakasam, B Prakash Rao and Goli Divakar: Formulation development and optimization of controlled porosity osmotic pump tablets of diclofenac sodium. International Journal of Pharmacy and Pharmaceutical Sciences. 2011; 3:80-87.

13. Suvakanta Dash. Kinetic modeling on drug release from controlled Drug delivery systems. Acta Poloniae Pharmaceutica - Drug Research. 2010; 67: 217-223.

14. Subramaniam Kannan, Rangasamy Manivannan, Ayyasamy Balasubramaniam and Natesan Senthil Kumar: Formulation and evaluation of aspirin delayed release tablet. Pharmacie Globale 2010; 1: 1-3. 